\title{
Steady-State Performance of Wide Parabolic-Shaped Slider Bearings with a Couple Stress Fluid
}

Jaw-Ren Lin

Professor, Department of Mechanical Engineering, Nanya Institute of Technology, P.O. Box 324-22-59, Chung-Li, Taiwan., jrlin@nanya.edu.tw

Yu-Ming Lu

Senior Student, Department of Mechanical Engineering, Nanya Institute of Technology, P.O. Box 324-22-59, Chung-Li, Taiwan.

Follow this and additional works at: https://jmstt.ntou.edu.tw/journal

Part of the Mechanical Engineering Commons

\section{Recommended Citation}

Lin, Jaw-Ren and Lu, Yu-Ming (2004) "Steady-State Performance of Wide Parabolic-Shaped Slider Bearings with a Couple Stress Fluid," Journal of Marine Science and Technology. Vol. 12: Iss. 4, Article 2.

DOI: $10.51400 / 2709-6998.2242$

Available at: https://jmstt.ntou.edu.tw/journal/vol12/iss4/2

This Research Article is brought to you for free and open access by Journal of Marine Science and Technology. It has been accepted for inclusion in Journal of Marine Science and Technology by an authorized editor of Journal of Marine Science and Technology. 


\title{
STEADY-STATE PERFORMANCE OF WIDE PARABOLIC-SHAPED SLIDER BEARINGS WITH A COUPLE STRESS FLUID
}

\author{
Jaw-Ren Lin* and Yu-Ming Lu**
}

Key words: slider bearings, parabolic-shaped film, steady-state performance, couple stress fluids, micro-continuum theory.

\section{ABSTRACT}

According to the Stokes micro-continuum theory, the effects of couple stresses upon the steady-state performance of wide parabolicshaped slider bearings are presented in this paper. To account for the couple stress effects arising from a Newtonian lubricant blended with various additives, the modified non-Newtonian Reynolds-type equation is derived using the Stokes motion equations together with the continuity equation. Comparing with the traditional Newtonianlubricant case, the effects of couple stresses characterized by the couple stress parameter signify an improvement in the steady-state performance. Increasing values of the couple stress parameter increases the bearing load-carrying capacity and reduces the required volume flow rate and the friction parameter. Compared to the inclined plane bearing, the parabolic-shaped slider lubricated with couple stress fluids results in a higher load-carrying capacity and a smaller required volume flow rate especially for the bearing designed at a larger value of the profile parameter.

\section{INTRODUCTION}

Slider bearings are often designed for supporting the transverse load in engineering applications. Bearing characteristics for different film shapes have been analyzed by Cameron [5], Pinkus and Sternlicht [18], and Hamrock [8]. However, these studies focus upon the use of a Newtonian fluid. In order to improve the lubricating performance, the increasing use of a Newtonian lubricant blended with various additives such as suspensions or long-chained polymers has been emphasized. Since the conventional continuum theory cannot accurately describe the flow behavior of these kinds of fluids, various micro-continuum theories are proposed by Ariman and Sylvester [1,2] and Stokes [21]. Among these micro-continuum theories the Stokes

Paper Submitted 06/11/04, Accepted 08/30/04. Author for Correspondence: Jaw-Ren Lin.E-mail: jrlin@nanya.edu.tw.

*Professor, Department of Mechanical Engineering, Nanya Institute of Technology, P.O. Box 324-22-59, Chung-Li, Taiwan.

**Senior Student, Department of Mechanical Engineering, Nanya Institute of Technology, P.O. Box 324-22-59, Chung-Li, Taiwan. theory [21] is the simplest one, which allows for polar effects such as the presence of couple stresses, body couples, and non-symmetric tensors. It is intended to take into account of particle-size effects, and is of importance for industrial and scientific applications of pumping fluids such as synthetic fluids, polymer-thickened oils, liquid crystals, and animal bloods.

Applying the couple stress fluid model, many articles concerning the fluid film lubricated bearings have been investigated. From the studies of squeeze film characteristics in finite plates by Ramanaiah [20], in partial journal bearings by Lin [12] and in sphere-plate bearings by Lin [14], the use of couple stress fluids as lubricants is found to increase the squeeze-film loadcarrying capacity and lengthen the response time of the squeeze film action. From the researches of the squeeze film behavior with reference to synovial joints in cylinders by Bujurke and Jayaraman [3] and in hemispherical bearings by Lin [9], the effects of couple stresses provide a reduction in the velocity and the displacement of the rotor center and therefore increase the minimum permissible height. From the analysis of rolling contact bearings by Bujurke and Naduvinami [4] and Das [6], the presence of couple stresses is shown to increase the load-carrying capacity and, hence, the maximum Hertzian pressure. From the prediction of externally pressurized bearing performances by Gupta and Sharma [7] and Lin [13], the couple stress effects signify an improvement in the dynamic stiffness and damping characteristics. According to the studies of journal bearings by Mokhiamer et al. [17] and Lin [10, 11, 15] and slider bearings by Ramanaiah [19] and Lin et al. [16], the effects of couple stresses are observed to reduce the friction parameter and result in longer bearing life.

Although the lubrication performance of the inclined-plane slider bearings with couple stress fluids has been analyzed by Ramanaiah [19] and Lin et al. [16], we have not yet understood how the couple stress effects affect the slider bearings with parabolic-film shapes. To provide more information in bearing designing, a further study is therefore motivated. 


\begin{abstract}
dimensional form.

$$
\begin{aligned}
& \frac{\partial u^{*}}{\partial x^{*}}+\frac{\partial w^{*}}{\partial z^{*}}=0 \\
& \frac{\partial p^{*}}{\partial x}=\frac{\partial^{2} u^{*}}{\partial z^{* 2}}-l^{* 2} \frac{\partial^{4} u^{*}}{\partial z^{* 4}} \\
& \frac{\partial p^{*}}{\partial z^{*}}=0
\end{aligned}
$$
\end{abstract}

ANALYSIS

On the basis of the Stokes micro-continuum theory, the effects of couple stresses on the steady-state performance of wide parabolic-shaped slider bearings are investigated. The slider bearing of length $L$ with sliding velocity $U$ is considered in Figure 1, in which the lubricant is taken to be a Stokes couple stress fluid, and the parabolic film profile is described by:

$$
h(x)=h_{m}+h_{p}(x)=h_{m}+\frac{d}{L}\left(L-2 x+\frac{x^{2}}{L}\right)
$$

where $h_{m}$ is the minimum film thickness at the outlet and $\mathrm{d}$ denotes the shoulder height of the bearing. In order to obtain the hydrodynamic lubrication equation, it is convenient to normalize the related quantities. Under the assumptions that the lubricant film is thin [8], the fluid inertia is small, and the body forces and body couples are absent, the continuity equation and the motion equations in the $x$ and $y$ directions can be expressed in a non-

where the non-dimensional quantities are defined by:

$$
\begin{aligned}
& x^{*}=\frac{x}{L}, z^{*}=\frac{z}{h_{0}}, u^{*}=\frac{u}{U}, w^{*}=\frac{L}{U h_{0}} w \\
& p^{*}=\frac{p h_{0}^{2}}{\mu U L}, l^{*}=\frac{l}{h_{0}}=\frac{(\eta / \mu)^{1 / 2}}{h_{0}}
\end{aligned}
$$

In these equations $u^{*}$ and $w^{*}$ represent the non-

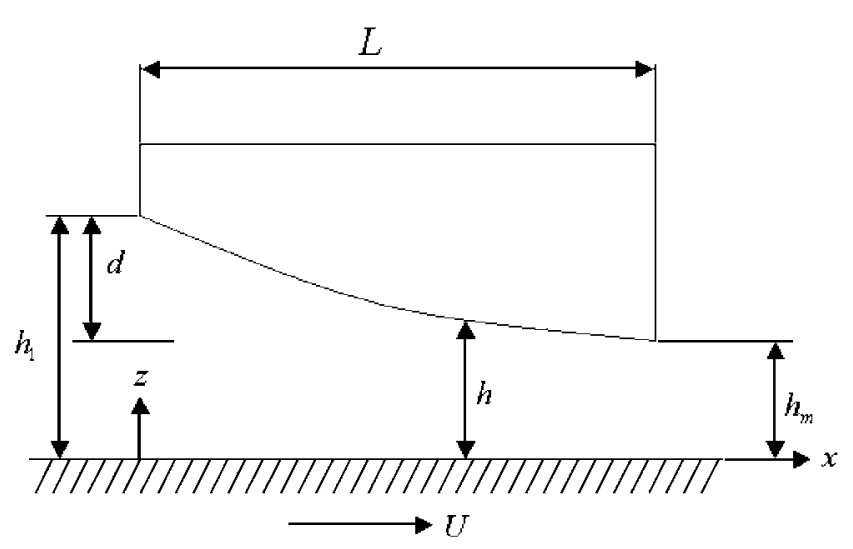

Fig. 1. Bearing geometry of a parabolic-shaped slider. dimensional velocity components in the $x$ and the $z$ directions respectively, $p^{*}$ is the non-dimensional pressure, is the reference film thickness, $\mu$ is the shear viscosity, and $\eta$ is a new material constant with the dimension of momentum and is responsible for the couple stress property. Its value could be determined by some experiments as discussed by Stokes [21]. The dimension of $l=(\eta / \mu)^{1 / 2}$ is of length. This length could be identified as the characteristic material length or the molecular length of the polar suspensions in a non-polar fluid. The effects of couple stresses are therefore dominated through the dimensionless couple stress parameter, $l^{*}=l / h_{0}$. If $\eta=0$, thereafter $l^{*}=0$, the classical form of a Newtonian lubricant is recovered from equation (3). The boundary conditions of $u^{*}$ and $w^{*}$ are the no-slip conditions and the non-couple stress conditions.

$$
\begin{aligned}
& \left.u^{*}\right|_{z^{*}=0}=1,\left.u^{*}\right|_{z^{*}=h^{*}=0,} \\
& \left.\frac{\partial^{2} u^{*}}{\partial z^{* 2}}\right|_{z^{*}=0}=\left.\frac{\partial^{2} u^{*}}{\partial z^{* 2}}\right|_{z^{*}=h^{*}}=0, \\
& \left.w^{*}\right|_{z^{*}=0},\left.w^{*}\right|_{z^{*}=h^{*}=0}=0
\end{aligned}
$$

where the non-dimensional film profile is written from equation (1) as:

$$
h^{*}=h_{m}^{*}+h_{p}^{*}=h_{m}^{*}+\delta\left(1-2 x^{*}+x^{* 2}\right)
$$

In this equation $h^{*}=h / h_{0}, h_{m}^{*}=h_{m} / h_{0}, h_{p}^{*}=h_{p} / h_{0}$ and $\delta$ represents the profile parameter of the bearing.

$$
\delta=\frac{d}{h_{0}}
$$

Integrating equation (3) and (4) with the boundary conditions of $u^{*}$ one can obtain the expression of the non-dimensional velocity component $u^{*}$

$$
\begin{aligned}
& u^{*}=1-\frac{z^{*}}{h^{*}} \\
& +\frac{1}{2} \frac{d p^{*}}{d x^{*}}\left\{z^{*}\left(z^{*}-h^{*}\right)+2 l^{* 2}\left\{1-\frac{\cosh \left[\left(2 z^{*}-h^{*}\right) /\left(2 l^{*}\right)\right]}{\cosh \left[h^{*} /\left(2 l^{*}\right)\right]}\right\}\right.
\end{aligned}
$$

Integrating the continuity equation (2) with respect to $z^{*}$ with the boundary conditions of $w$ given in equation (6), one can obtain the non-dimensional modified non-Newtonian Reynolds-type equation governing the hydrodynamic film pressure for the slider bearing with a parabolic-shaped film. 


$$
\frac{d}{d x^{*}}\left[f^{*}\left(h^{*}, l^{*}\right) \frac{d p^{*}}{d x^{*}}\right]=6 \frac{d h_{p}^{*}}{d x^{*}}
$$

where the function $f^{*}$ is defined by:

$$
f^{*}\left(h^{*}, l^{*}\right)=h^{* 3}-12 l^{*^{2}}\left[h^{*}-2 l^{*} \tanh \left(\frac{h^{*}}{2 l^{*}}\right)\right]
$$

As the value of $l^{*}$ approaches zero, the function $f^{*}$ yields the results of $h^{* 3}$, the lubrication equation (10) reduces to the classical form for a Newtonian-lubricant case.

\section{BEARING CHARACTERISTICS}

Integrating the non-dimensional Reynolds-type equation (10) once with respect to $x^{*}$ gives

$$
\frac{d p^{*}}{d x^{*}}=6 \frac{h_{p}^{*}\left(x^{*}\right)}{f^{*}\left(h^{*}, l^{*}\right)}+c_{1} \frac{1}{f^{*}\left(h^{*}, l^{*}\right)}
$$

where $c_{1}$ is the integration constant. Integrating again with the zero-pressure condition at the inlet results in the film pressure distribution.

$$
p^{*}\left(x^{*}\right)=6 f_{A}\left(x^{*}, h_{m}^{*}\right)+c_{1} f_{C}\left(x^{*}, h_{m}^{*}\right)
$$

where

$$
\begin{aligned}
& f_{A}\left(x^{*}, h_{m}^{*}\right)=\int_{x^{*}=0}^{x^{*}} \frac{h_{p}^{*}\left(x^{*}\right)}{f^{*}\left(h^{*}, x^{*}\right)} d x^{*} \\
& f_{C}\left(x^{*}, h_{m}^{*}\right)=\int_{x^{*}=0}^{x^{*}} \frac{1}{f^{*}\left(h^{*}, x^{*}\right)} d x^{*}
\end{aligned}
$$

The integration constant can be evaluated by using the zero-pressure condition at the outlet.

$$
c_{1}\left(h_{m}^{*}\right)=\frac{-6 f_{A}\left(x^{*}=1, h_{m}^{*}\right)}{f_{C}\left(x^{*}=1, h_{m}^{*}\right)}
$$

Evaluating the lubricant film thickness at the location where the pressure gradient is equal to zero gives from equation (12) the following position.

$$
x_{M}^{*}=1-\left(\frac{-c}{6 \delta}\right)^{1 / 2}
$$

When the location of the maximum pressure is obtained, the maximum pressure can be found from the expression of $p_{M}^{*}=p^{*}\left(x^{*}=x_{M}^{*}\right)$.

The non-dimensional load-carrying capacity is computed by integrating the film pressure over the film region.

$$
W^{*}=\frac{W h_{0}^{2}}{\mu U L^{2} B}=\int_{x^{*}=0}^{1} p^{*} d x^{*}
$$

where $B$ denotes the width of the bearing. Performing the integration results in

$$
W^{*}=6 F_{A}\left(h_{m}^{*}\right)+c_{1}\left(h_{m}^{*}\right) F_{C}\left(h_{m}^{*}\right)
$$

In the equation, $F_{A}$ and $F_{C}$ are determined by the following double integrals.

$$
\begin{aligned}
F_{A}\left(h_{m}^{*}\right) & =\int_{x^{*}=0}^{1} f_{A}\left(x^{*}, h_{m}^{*}\right) d x^{*} \\
& =\int_{x^{*}=0}^{1} \int_{x^{*}=0}^{x^{*}} \frac{h_{p}^{*}\left(x^{*}\right)}{f^{*}\left(h^{*}, x^{*}\right)} d x^{*} d x^{*} \\
F_{C}\left(h_{m}^{*}\right) & =\int_{x^{*}=0}^{1} f_{C}\left(x^{*}, h_{m}^{*}\right) d x^{*} \\
& =\int_{x^{*}=0}^{1} \int_{x^{*}=0}^{x^{*}} \frac{1}{f^{*}\left(h^{*}, x^{*}\right)} d x^{*} d x^{*}
\end{aligned}
$$

The non-dimensional shearing stress is calculated by using the expression of $u^{*}$.

$$
\tau_{z x}^{*}=\frac{\tau_{z x} h_{0}}{\mu U}=\frac{\partial u^{*}}{\partial z^{*}}-l^{* 2} \frac{\partial^{3} u^{*}}{\partial z^{* 3}}
$$

The non-dimensional shear force components acting upon the lower and upper surfaces are

$$
\begin{aligned}
& F_{L}^{*}=\frac{F_{L} h_{0}}{\mu U L B}=\int_{x^{*}=0}^{1}\left[\tau_{z x}^{*}\right]_{z^{*}=0} d x^{*} \\
& F_{U}^{*}=\frac{F_{U} h_{0}}{\mu U L B}=\int_{x^{*}=0}^{1}\left[-\tau_{z x}^{*}\right]_{z^{*}=h} * d x^{*}
\end{aligned}
$$

Using equations (22) and (9) yields

$$
\begin{aligned}
& F_{L}^{*}=\frac{F_{L} h_{0}}{\mu U L B}=\int_{x^{*}=0}^{1}\left[-\frac{1}{h^{*}}-\frac{h^{*}}{2} \frac{\partial p^{*}}{d x^{*}}\right] d x^{*} \\
& F_{U}^{*}=\frac{F_{U} h_{0}}{\mu U L B}=\int_{x^{*}=0}^{1}\left[+\frac{1}{h^{*}}-\frac{h^{*}}{2} \frac{\partial p^{*}}{d x^{*}}\right] d x^{*}
\end{aligned}
$$

The friction coefficient can be evaluated by $\left(-F_{L}\right) /$ $W$. Making use of the non-dimensional expressions of $F_{L}^{*}$ and $W^{*}$, one can obtain the friction parameter.

$$
\mu_{p}=-\frac{F_{L}}{W} \cdot \frac{L}{h_{0}}=-\frac{F_{L}^{*}}{W^{*}}
$$

The non-dimensional volume flow rate in the $x$ direction is defined as

$$
Q_{0}^{*}=\frac{q_{x}}{U h_{0} B}=\int_{z^{*}=0}^{h^{*}} u^{*} d z^{*}
$$


Using the expression of $u^{*}$ and evaluating the flow rate where $\partial p^{*} / \partial x^{*}=0$ gives

$$
Q_{0}^{*}=\left[\frac{1}{h^{*}}\right]_{x^{*}=x_{M}^{*}}
$$

The temperature rise due to the work done against the shearing stresses may be transferred by radiation, conduction or convection. The bulk heat flow is carried by the convection of the lubricant. Following the procedure by Hamrock [8], one can obtain the temperature rise $t_{m}$ expressed in a dimensionless form.

$$
t_{m}^{*}=\frac{\rho g J C_{p} h_{0}^{2}}{\mu U L} t_{m}=-\frac{F_{L}^{*}}{Q_{0}^{*}}
$$

where $\rho$ is the density of the lubricant, $g$ is the gravitational acceleration, $J$ is the Joule's mechanical equivalent of heat, and $C_{P}$ is the specific heat of the lubricant at constant pressure.

\section{RESULTS AND DISCUSSION}

The effects of couple stresses upon the steadystate performance of wide parabolic-shaped slider bearings are observed through the dimensionless couple stress parameter defined by $l^{*}=l / h_{0}=(\eta / \mu)^{1 / 2} / h_{0}$. Since the dimension of the ratio $(\eta / \mu)$ is of length squared, it characterizes the microstructure size. Therefore the couple stress parameter $l^{*}$ gives the mechanism of interaction of the couple stress fluid with the slider bearing

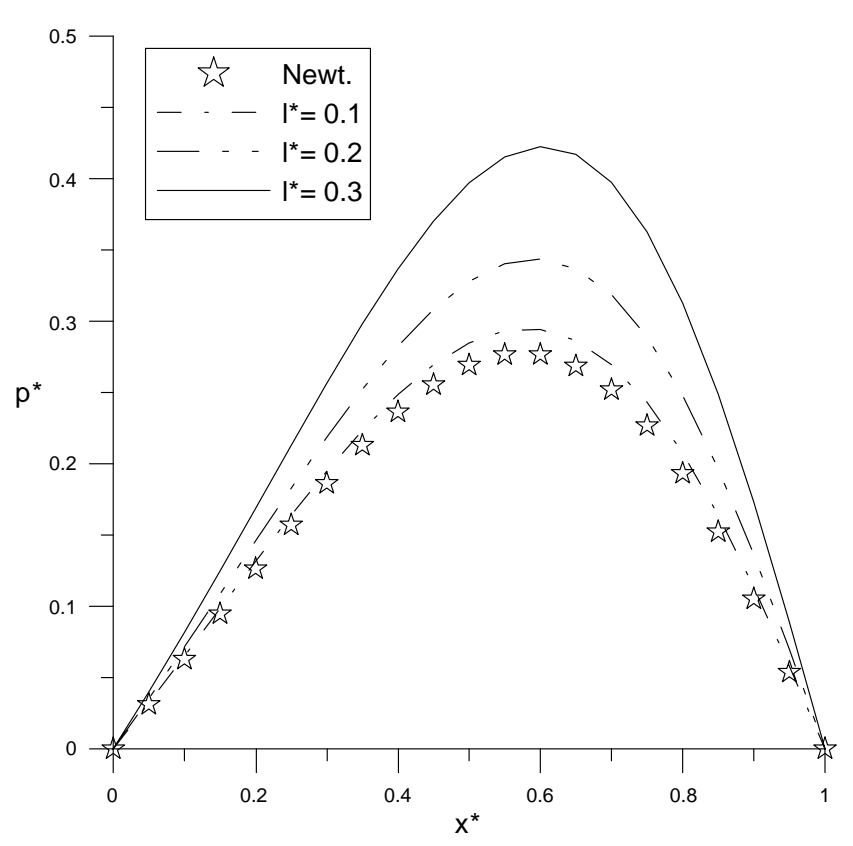

Fig. 2. Dimensionless film pressure as a function of $x^{*}$ for different $l^{*}$. geometry. As the value of $l^{*}$ approaches zero, the effects of couple stresses vanish, and the dimensionless nonNewtonian modified Reynolds-type equation reduces to the Newtonian-lubricant case [8]. In order to obtain the bearing characteristics, the numerical computations are performed by choosing the reference film thickness $h_{0}=$ $h_{m}$, the profile parameter $\delta=0.2-2.8$ and the couple stress parameter $l^{*}=0-0.5$.

Steady-state performance. Figure 2 shows the dimensionless film pressure $x^{*}$ as a function of $l^{*}$ for different values of $l^{*}$. It is observed that the effects of couple stresses $\left(l^{*}=0.1\right)$ are to increase $p^{*}$ as compared to the Newtonian-lubricant case. Increasing values of the couple stress parameter $\left(l^{*}=0.2,0.3\right)$ increase the effects of couple stresses upon the film pressure. Figure 3 presents the dimensionless load-carrying capacity $W^{*}$ as a function of profile parameter $\delta$ for different values of $l^{*}$. Since the effects of couple stresses provide an increase in the film pressure, the integrated load-carrying capacity is similarly affected. Compared to the Newtonian-lubricant case, the effects of couple stresses are observed to increase the load-carrying capacity. The increase in $W^{*}$ is more accentuated at a higher value of the couple stress parameter $\left(l^{*}=0.3\right)$ for the parabolic slider bearing with medium profile parameter (about $\delta$ $=1.1$ ). Figure 4 describes the dimensionless shear force components $F_{U}^{*}$ and $F_{L}^{*}$ as a function of profile parameter $\delta$ for different values of $l^{*}$. It is shown that the shear force component $F_{U}^{*}$ decreases with increasing values of $\delta$, but the shear force component $F_{L}^{*}$ increases with profile parameter. Comparing with the Newtonian-

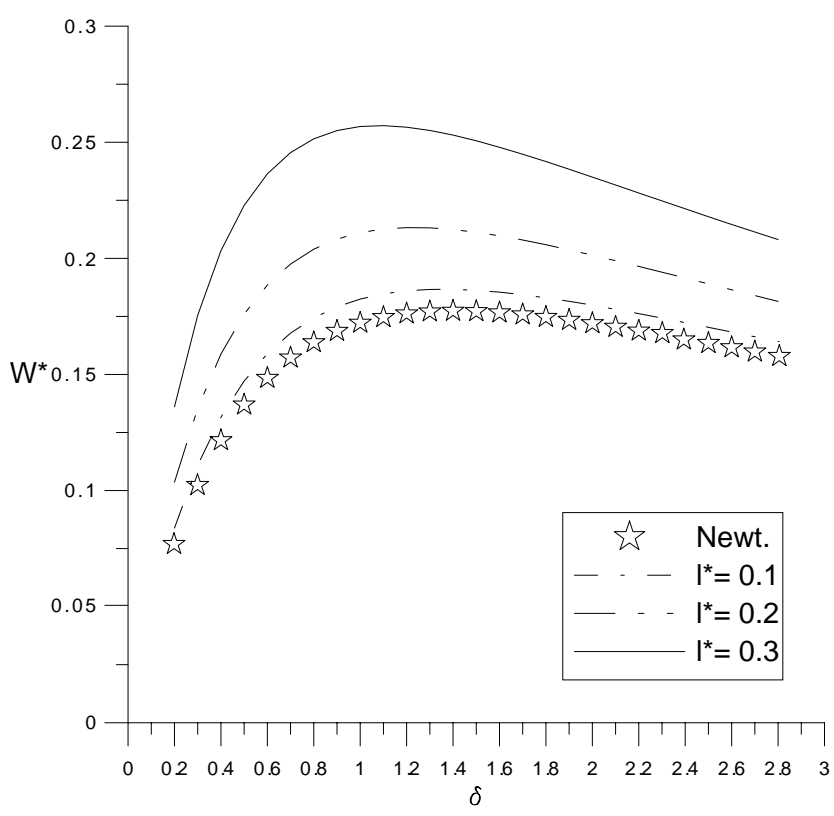

Fig. 3. Dimensionless load capacity as a function of profile parameter for different $l^{*}$ 
lubricant case, the effects of couple stresses signify a decrease in the shear force components under large values of the profile parameter. Figure 5 presents the friction parameter $\mu_{p}$ as a function of profile parameter $\delta$ for different values of $l^{*}$. The value of $\mu_{p}$ is observed to decrease with $\delta$ to attain a minimum, and thereafter increases with $\delta$. Comparing with the Newtonianlubricant case, the effects of couple stresses provide a decrease in the value of $\mu_{p}$. Moreover, the smaller the profile parameter, the more the couple stresses decrease the friction parameter of the bearing. Figure 6 shows the dimensionless volume flow rate $Q_{0}^{*}$ as a function of profile parameter $\delta$ for different values of $l^{*}$. It is found that the value of $Q_{0}^{*}$ increases with the value of $\delta$. Compared to the Newtonian-lubricant case, the required volume flow rate is reduced by the presence of couple stresses especially at a higher profile parameter. The dimensionless adiabatic temperature rise $t_{m}^{*}$ as a function of profile parameter $\delta$ for different values of $l^{*}$ is depicted in Figure 7. Higher values of $\delta$ yield lower values of $t_{m}^{*}$, since it requires lager amount of $Q_{0}^{*}$. It is also found that the effects of couple stresses increase the temperature rise, because of the reduced volume flow rate due to the presence of couple stresses.

As discussed by Stokes [21], the couple stress fluid model is intended to describe the flow behavior of a Newtonian lubricant blended with various additives. Comparing with a Newtonian fluid, the couple stress fluids possesses a higher specific weight. For the same parabolic-shaped surface, the couple stress fluid in the bearing is expected to have a lower flowing velocity and

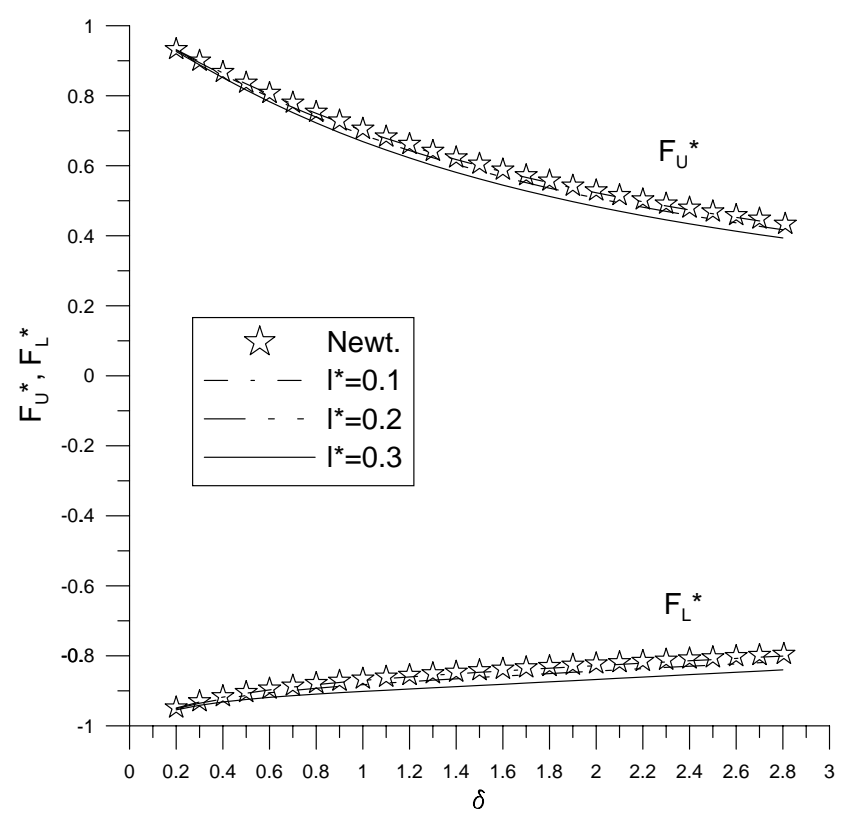

Fig. 4. Shear force components as a function of profile parameter for different $l^{*}$. a smaller volume flow rate. As a consequence, the bearing load-carrying capacity is enhanced.

Optimal shoulder height. The shoulder height that produces a maximum pressure can be obtained calculating the film pressure (13) at the location $x_{M}^{*}$ given in equation (17). Figure 8 shows the dimensionless maxi-

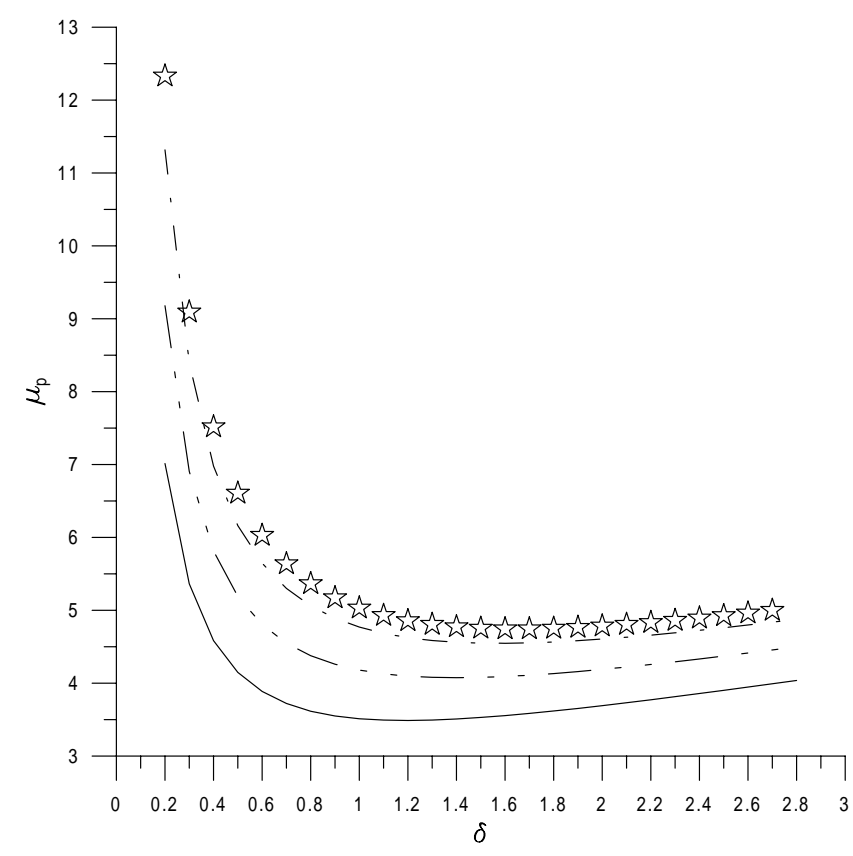

Fig. 5. Friction parameter as a function of profile parameter for different $l^{*}$.

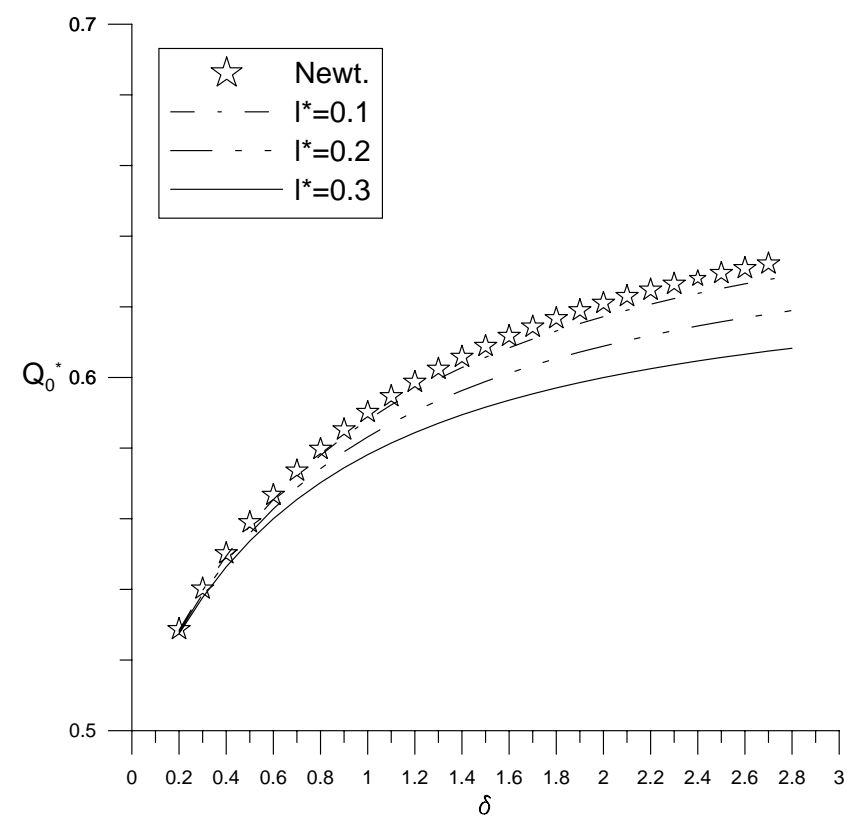

Fig. 6. Volume flow rate as a function of profile parameter for different $l^{*}$. 


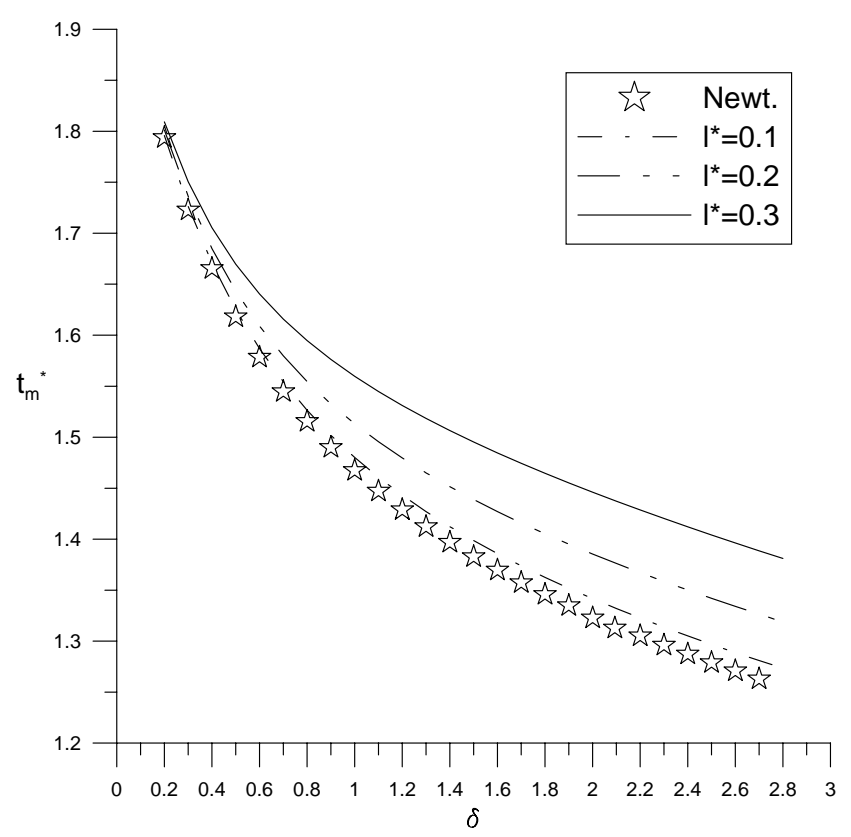

Fig. 7. Adiabatic temperature rise as a function of profile parameter for different $l^{*}$.

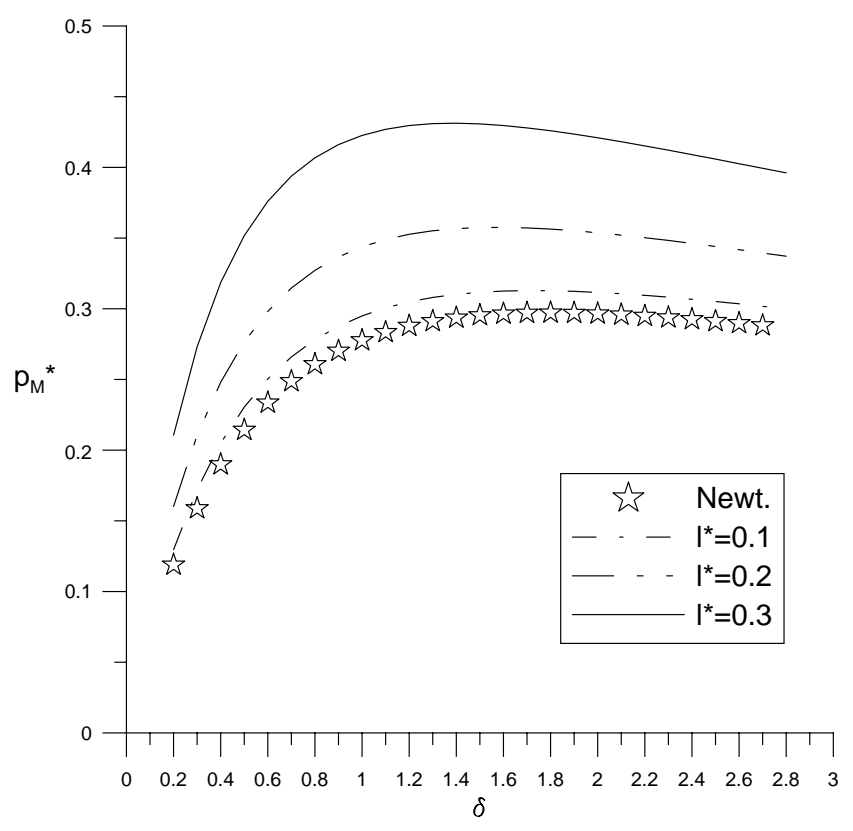

Fig. 8. Maximum pressure as a function of profile parameter for different $l^{*}$.

mum pressure $p_{M}^{*}$ as a function of profile parameter $\delta$ for different values of $l^{*}$. This Figure is helpful in practical designs, since if the description of the profile surface (1) is known, one can predict what the minimum film thickness should be from the value of $\delta_{o p t}$. From the

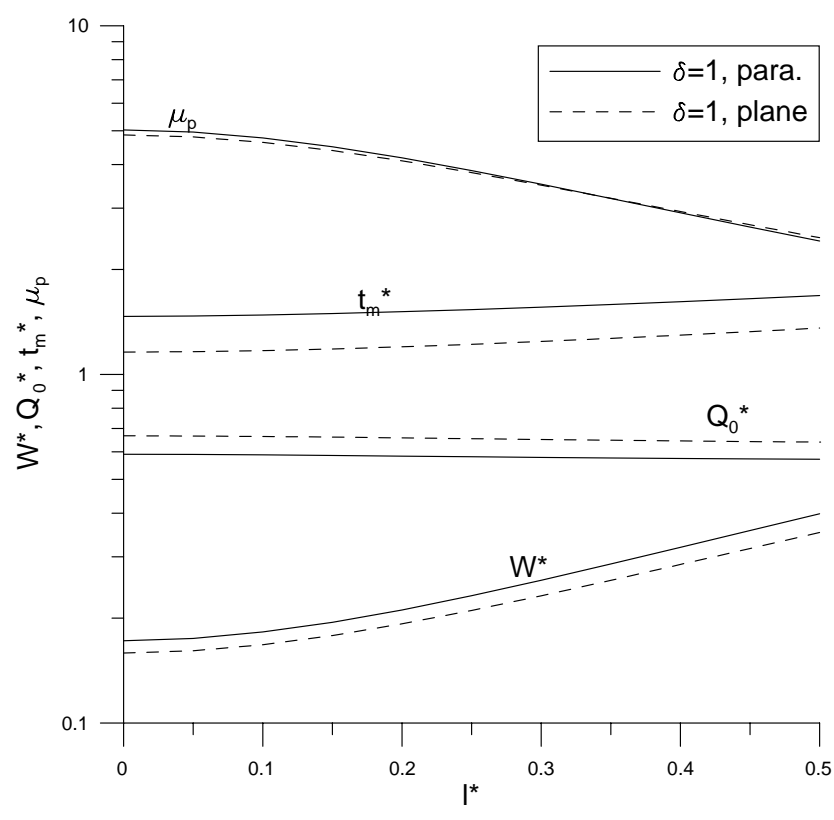

Fig. 9. Comparison of bearing characteristics for profile parameter $\delta$ $\mathbf{= 1}$.

Figure, it is observed that: $\delta_{o p t}=1.8$ for the Newtonianlubricant case; $\delta_{o p t}=1.7$ for $l^{*}=0.1 ; \delta_{o p t}=1.6$ for $l^{*}=$ $0.2 ; \delta_{\text {opt }}=1.4$ for $l^{*}=0.3$.

Comparing with the inclined-plane bearing. To provide more information for engineers, comparisons of bearing characteristics between the parabolic-shaped surface and the plane-inclined surface for $\delta=1$ to $\delta=2$ are presented in Figures 9 and 10. The results of the plane-inclined bearing are evaluated from Lin et al. [16] under the wide bearing approximation. It is observed from Figure 9 that the parabolic-shaped bearing under $\delta$ $=1$ results in a closed value of $\mu_{p}$, a smaller value of $Q_{0}^{*}$ and a higher value of $t_{m}^{*}$ and $W^{*}$, as compared to the plane-inclined bearing. Furthermore, a larger difference of the steady-state performance between the two types of bearings is more pronounced for the profile parameter given by $\delta=2$ as observed in Figure 10 .

The difference of the steady-state performance between the two types of bearings can be realized from the bearing geometry. The non-dimensional plane inclined film profile from [16] is described by:

$$
h^{*}=h_{m}^{*}+h_{p}^{*}=h_{m}^{*}+\delta\left(1-x^{*}\right)
$$

Under the same values of $x^{*}$ and $x^{*}\left(0<x^{*}<1\right)$, the parabolic-shaped bearing results in a smaller film height. A smaller amount of $Q_{0}^{*}$ is required and, hence, a higher value of $W^{*}$ is obtained and a higher value of $t_{m}^{*}$ is achieved for the parabolic-shaped bearing. Increasing 


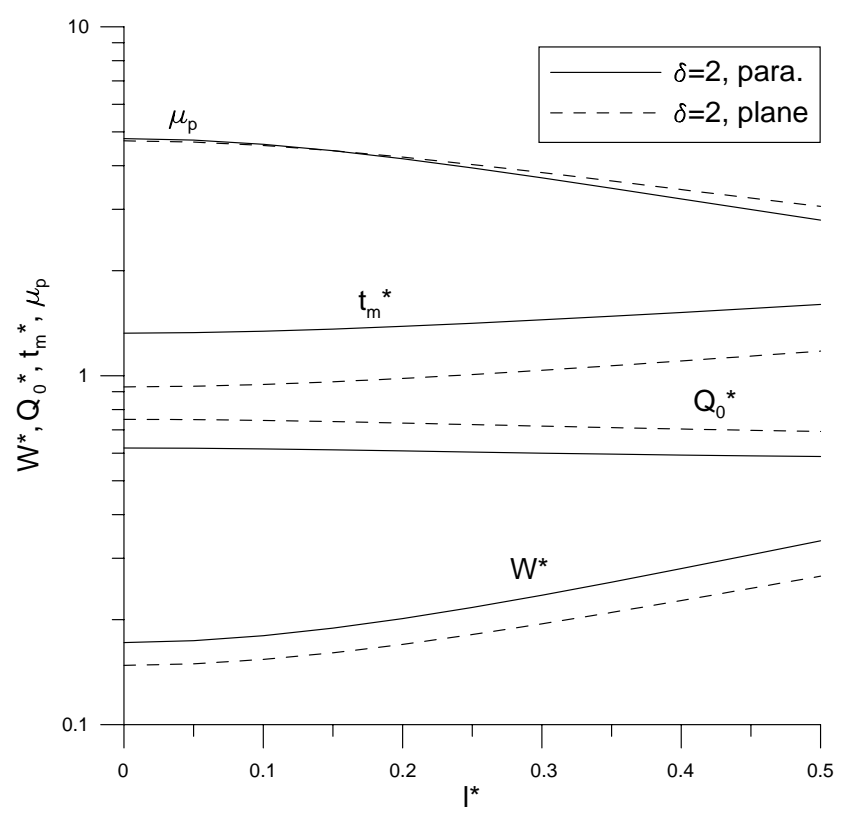

Fig. 10. Comparison of bearing characteristics for profile parameter $\boldsymbol{\delta}=\mathbf{2}$.

the value of $\delta$ from $\delta=1$ to $\delta=2$ increases the filmheight difference between the two types of bearings. As a result, a larger difference of the steady-state performance is observed in Figures 9 and 10.

\section{CONCLUSIONS}

The effects of couple stresses upon the steadystate performance of a wide parabolic-shaped slider bearing are studied according to the Stokes microcontinuum theory. Using the Stokes motion equations together with the continuity equation, the non-Newtonian modified Reynolds-type equation is derived to account for the couple stress effects arising from a Newtonian lubricant blended with various additives. From the results obtained and discussed, conclusions can be drawn as follows.

The effects of couple stresses characterized by the couple stress parameter signify an improvement in the steady-state performance as compared to the traditional Newtonian-lubricant case. Increasing values of the couple stress parameter increases the bearing loadcarrying capacity, and reduces the required volume flow rate and the friction parameter. Comparing with the inclined plane bearing case, the parabolic-shaped slider lubricated with couple stress fluids results in a higher load-carrying capacity and a smaller required volume flow rate especially for the bearing designed at a larger value of the profile parameter. The present study provides engineers useful information in bearing designs.

\section{REFERENCES}

1. Ariman, T. and Sylvester, N.D., "Microcontinuum Fluid Mechanics, a Review," Int. J. Eng. Sci., Vol. 11, pp. 905930 (1973).

2. Ariman, T. and Sylvester, N.D., "Applications of Microcontinuum Fluid Mechanics," Int. J. Eng. Sci., Vol. 12, pp. 273-293 (1974).

3. Bujurke, N.M. and Jayaraman, G., "The Influence of Couple Stresses in Squeeze Films," Int. J. Mech. Sci., Vol. 24, pp. 369-76 (1982).

4. Bujurke, N.M. and Naduvinami, N.G., "The Lubrication of Lightly Cylinders in Combined Rolling, Sliding and Normal Motion with Couple Stress Fluid," Int. J. Mech. Sci., Vol. 32, pp. 969-979 (1990).

5. Cameron, A., The Principles of Lubrication, Longmans Green and Co. Ltd., London (1966).

6. Das, D.C., "Elastohydrodynamic Lubrication Theory of Line Contacts: Couple Stress Fluid Model," STLE Tribol. Trans., Vol. 40, pp. 353-359 (1997).

7. Gupta, R.S. and Sharma, L.G., "Analysis of Couple Stress Lubricant in Hydrostatic Thrust Bearings," Wear, Vol. 48, pp. 257-269 (1988).

8. Hamrock, B.J., Fundamentals of Fluid Film Lubrication, McGraw-Hill, Inc., New York, 1994.

9. Lin, J.R., "Couple-Stress Effects on the Squeeze Film Characteristics of Hemispherical Bearings with Reference to Synovial Joints," Int. J. Appl. Mech. Eng., Vol. 1, pp. 317-332 (1996).

10. Lin, J.R., "Effects of Couple Stresses on the Lubrication of Finite Journal Bearing," Wear, Vol. 206, pp. 171-178 (1997).

11. Lin, J.R., "Static Characteristics of Rotor Bearing System Lubricated with Couple Stress Fluids," Comput. Struct., Vol. 62, No. 1, pp. 175-184 (1997).

12. Lin, J.R., "Squeeze Film Characteristics of Long Partial Journal Bearings Lubricated with Couple Stress Fluids," Tribol. Int., Vol. 30, pp. 53-58 (1997).

13. Lin, J.R., "Static and Dynamic Behavior of Externally Pressurized Circular Step Thrust Bearings Lubricated with Couple Stress Fluids," Tribol. Int., Vol. 32, pp. 207216 (1999).

14. Lin, J.R., "Squeeze Film Characteristics Between a Sphere and a Flat Plate: Couple Stress Fluid Model," Comput. Struct., Vol. 75, pp. 73-80 (2000).

15. Lin, J.R., "Linear Stability Analysis of Rotor Bearing System: Couple Stress Fluid Model," Comput. Struct., Vol. 79, pp. 801-809 (2001).

16. Lin, J.R., Lu, R.F., and Chang, T.B., "Derivation of Dynamic Couple-Stress Reynolds Equation of SlidingSqueezing Surfaces and Numerical Solution of Plane Inclined Slider Bearings," Tribol. Int., Vol. 36, pp. 679- 
685 (2003).

17. Mokhiamer, U.M., Crosby, W.A., and El-Gamal H.A., "A Study of a Journal Bearing Lubricated by Fluids with Couple Stress Considering the Elasticity of the Linear," Wear, Vol. 224, pp. 191-201 (1999).

18. Pinkus, O. and Sternlicht, B., Theory of Hydrodynamic Lubrication, McGraw Hill, New York, (1961).
19. Ramanaish, G., "Slider Bearings Lubricated by Fluids with Couple Stress," Wear, Vol. 52, pp. 27-36 (1979).

20. Ramanaish, G., "Squeeze Films between Finite Plates Lubricated by Fluids with Couple Stress," Wear, Vol. 54, pp. 315-320 (1979).

21. Stokes, V.K., "Couple Stresses in Fluids," Phys. Fluids, Vol. 9, pp. 1709-1715 (1966). 